
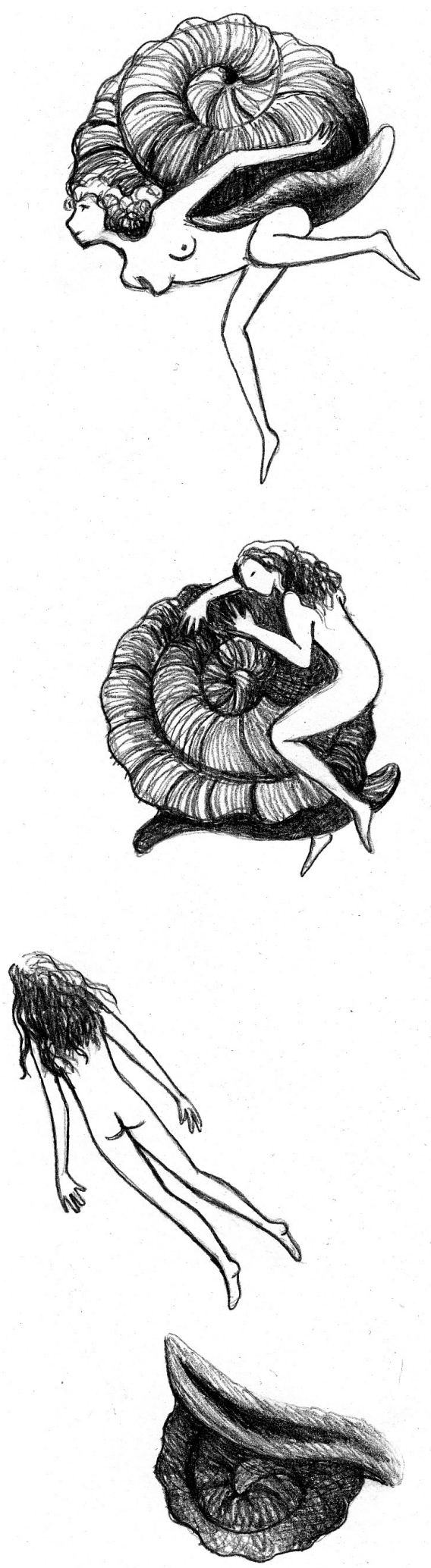

Ilustración de Karina Siliezar Delgado. Grafito sobre papel, 2018. 


\title{
Contribuciones Femeninas a la Poesía Guatemalteca
}

Franco Cerutti Frigerio ${ }^{1}$ Instituto de Estudios Latinoamericanos Universidad Nacional, Costa Rica

\begin{abstract}
Resumen
Este estudio forma parte de una más amplia investigación del IDELA sobre escritoras centroamericanas del siglo XX hasta los años ochenta. Guatemala es una nación donde muchas mujeres destacaron como poetas; otras escribieron novelas o hicieron periodismo; muchas de ellas mantuvieron una posición feminista.
\end{abstract}

Palabras claves: literatura de Centroamérica, poesía, mujeres

\begin{abstract}
This study is part of a larger research about Central American women writers during the XX Century up to the eighties. Guatemala is a nation here many women became outstanding poets; other ones were novelists and journalists; and many of them had a feminist position.
\end{abstract}

Keywords: Central American literature, poetry, women

$\mathbf{E}$ $n$ la presente investigación se pretende reunir una cantidad de datos, informaciones y evaluaciones críticas acerca de la actividad poética llevada a cabo en Guatemala por parte de la mujer, a partir del periodo colonial hasta la llamada generación del cuarenta. En una próxima investigación analizaremos la obra de las poetisas que han venido afirmándose entre aquella fecha y nuestros

1 Publicación póstuma. días, que también son muchas y que han cumplido con una labor notable. ${ }^{2}$

Aun cuando parte de la presente información conste en una que otra obra general sobre literatura guatemalteca o en algún compendio dedicado a la poseía en el germano país, se halla, en conjunto, bastante dispersa y no siempre es de fácil acceso. Consideramos que estas sencillas

2 Ver Repertorio Americano, Segunda Nueva Época, $n^{\circ} 27,2017$. 
acotaciones pueden tener alguna utilidad, inclusive didáctica, por cuanto ponen al alcance del estudiante, y del estudioso, noticias y apreciaciones que, de otra manera, deberían buscarse en diferentes textos y no siempre con la certeza de hallarlas.

Para comodidad de quienes los consulten, estos apuntes han sido ordenados cronológicamente a partir de la obra de Sor Juana de Maldonado y Paz, primera poetisa de la que se sepa algo concreto y que, nacida al terminarse el sigo XVI, murió en Santiago de los Caballeros de Guatemala en la segunda mitad del siglo XVII.

Antes de entrar de lleno en la faena de enfocar la poesía femenina de Guatemala en la época indicada, cabe hacer una breve referencia a la obra de quienes nos han precedido en esta clase de investigaciones. No son muchos, diríamos más bien que son pocos los tratadistas que se han ocupado ex profeso de la materia.

Solamente en la segunda mitad del siglo $\mathrm{XX}$, de acuerdo con la renovada tónica espiritual que enfatiza en el estudio y la revaloración de la mujer y de sus actividades, ha habido cierto interés específico por estudiar la producción literaria, y por ende poética, de la mujer guatemalteca. Como era de esperar, quienes impulsaron dichas investigaciones fueron prevalentemente mujeres, aun cuando sea de justicia recordar la valiosa aportación de varios estudios pertenecientes al llamado "sexo fuerte".

Señalamos entre las primeras, a la poetisa e historiadora de la literatura Luz Méndez de la Vega, catedrática universitaria y autora de obras antológicas y críticas como lo son La mujer en la literatura y los libros de texto, y Poetisas desmitificadoras. Entre los segundos, tenemos a Francisco Albizurez Palma, también catedrático de la Universidad de San Carlos de Guatemala y autor, en colaboración con la licenciada Catalina Barrios y Barrios, de una voluminosa Historia de la literatura guatemalteca de la que ya han salido dos gruesos tomos, siendo anunciada como inminente la publicación del tercero; el crítico, novelista y poeta Mario Alberto Carrera, autor de Panorama de la poesía femenina guatemalteca del siglo $X X$, muy bien redactada y con amplia información.

También cabe hacer mención -aunque hoy resulte un poco superada- de la Historia de la literatura guatemalteca de David Vela, en dos tomos, obra que, sin embargo, tiene el inconveniente de llegar únicamente a los primeros años del siglo XX dejando de lado todo lo que ha habido después.

De Francisco Albizurez Palma merecen también ser recordados dos trabajos de menos envergadura pero muy útiles en punto a información: los Grandes momentos de la literatura guatemalteca (1983) y el Diccionario de autores guatemaltecos (1984), ambos publicados por el Ministerio de Educación del vecino país.

Todos los textos señalados nos han sido de gran utilidad al llevar a cabo el presente ensayo y así queremos hacerlo constar. En ellos, además, quien tenga interés en profundizar estas investigaciones, encontrará una bibliografía detallada aunque, desgraciadamente, no muy abundante pues, como decíamos al principio, los estudios sobre figuras femeninas de la literatura 
guatemalteca se cuentan, más o menos, con los dedos de la mano.

\section{Sor Juana de Maldonado y Paz}

Es la primera figura femenina con que topamos al investigar el pretérito poético de Guatemala y su figura, después de cuatro siglos, sigue envuelta en las neblinas de la incertidumbre.

La "primera monja poetisa de América" nació en Santiago de los Caballeros de Guatemala en 1598, hija de padre español que contrajo matrimonio con doña Concepción de Quintanilla. Falleció en la misma ciudad en el año 1666, a los 68 más o menos, cuando sor Juana Inés de la Cruz contaba quince años de edad.

Como lo hace observar uno de los pocos estudiosos que se han dedicado a investigar su figura y lo poco que queda de su obra, Sor Juana había sido considerada una bella leyenda del siglo XVII, leyenda que surgió cuando el misionero Tomás Gage, originario de Irlanda, vino a Guatemala en el primer cuarto del siglo XVII.

Gage vivió en Antigua, Mixco, Pinula y Amatitlán, cuya parroquia abandonó para huir por otros países de América e ir luego hacia Inglaterra. Ya en Londres, en 1648, publicó su obra $A$ New Survey of the West Indians, con referencias a su viaje hacia el Nuevo Mundo. En esta obra, Gage concibe la América como fecunda pero incapaz de defender sus grandes dominios de otra potencia distinta de España; quizá pensaba que América perfectamente podría ser dominada por Inglaterra.
Tomás Gage describe muchos de los edificios de Antigua Guatemala y entre ellos habla del Convento de la Concepción; al referirse a él alude a una monja bella que tomó el hábito muy joven y vivió en un apartamento de mucho lujo exclusivo, con capilla particular y jardines, adornado con lámparas y pinturas de las mejores de la época. Informa que la monja era de la mejor sociedad y pertenecía a una familia adinerada, la del Gobernador Alonso Maldonado Paz, interino, nombrado a la muerte de Pedro de Alvarado por el virrey de Nueva España.

El misionero irlandés, además de describir la celda de la monja, se refiere a la conducta ambiciosa de aquella, la cual, según afirmación de Gage, provocó escándalo, hasta el punto de haber sido juzgada por la Inquisición, después de que el pintor Francisco Montúfar Bravo de la Laguna pintó el rostro de Sor Juana en un cuadro de Santa Lucía, y el de su padre, el Oidor Maldonado y Paz, en un cuadro de San Juan Bautista.

Por el contrario, fray Antonio Arochena, franciscano, no demerita a Sor Juana, sino la exalta como autora de versos magníficos.

Todos los datos anteriores resultaban en bello mito de la vida colonial. La leyenda de Sor Juana culminó en la novela La divina reclusa, del autor guatemalteco Máximo Soto Hall.

Algunos estudiosos, ya en el siglo XX, se han ocupado de la extraña monja. Así, J. Joaquín Pardo, en el diario El Imparcial -10 de junio de 1949- da a la publicidad un manuscrito que confirma la existencia de la monja Sor Juana de Maldonado y Paz, y 
la fidelidad del voto en el Convento de la Concepción, el 27 de diciembre de 1619.

El Instituto de Antropología e Historia de Guatemala publica, en el año 1957, una investigación de Ricardo Toledo Palomo, en donde se comprueba la existencia de la monja, a partir de la venta de una dependencia en el interior del Convento de la Concepción. Se da a conocer en esta investigación que el padre de Sor Juana fue le Oidor Juan Maldonado y Paz y no Alonso Maldonado de Paz, fiscal de Audiencia, como indica Gage; el Oidor mandó a fabricar a su costa una casa para ella, dentro del mismo convento; Maldonado y Paz era adinerado e influyente entre las autoridades religiosas, que le concedían tales prerrogativas.

Ernesto Chinchilla Aguilar llega a la conclusión de que el cronista colonial Tomás Gage fue el primero que habló de Sor Juana; Gage la describe "con el don y cualidad de poetisa". En 1946 (trescientos años después), se desvanece la incógnita de su existencia real. El escritor Mariano López Mayorical, en sus Investigaciones históricas, revela composiciones manuscritas e inéditas, como son el acta del Convento de la Concepción donde aparecen autógrafas las firmas de Sor Juana de la Concepción, nombre adoptado en el convento.

Mayorical, para tener la certeza de la existencia de Sor Juana, recurrió a constancias, tales como que el pintor Francisco de Montúfar trabajó por largo tiempo para el Convento de la Concepción, en donde hay pinturas que se le atribuyen y que representan a Sor Juana antes de ingresar al convento. Algunas de las afirmaciones de
Gage han sido confirmadas y apegadas a la verdad, según Mayorical.

Según nos afirma el mismo historiador, la poetisa y crítica literaria María Albertina Gámez, a quien tanto debe la moderna literatura guatemalteca en punto a investigaciones y rescates, "aseguraba haber tenido en sus manos un legajo de manuscritos relacionados con Sor Juana de la Concepción, los cuales consultó superficialmente en el Archivo y Biblioteca de México, noticia corroborada por Alfonso Carrillo Ramírez, según indica López Mayorical. Carrillo Ramírez, en verdad, ha tenido conocimiento de que en México existen documentos relacionados con el Oidor y con su hija Juana, entre los que se encuentra el acta parroquial de su partida de nacimiento que tuvo lugar en la Antigua Guatemala.

Pedro Arce y Valladres confirma la existencia de documentos relacionados con Sor Juana Maldonado y Paz, pertenecientes a la familia Asturias.

María de la Concepción Andueza se pronuncia, a su vez en favor y en defensa de Sor Juana de Maldonado y Paz, con base en una minuciosa investigación comparativa entre cronistas de la colonia". Concluye con que ninguno de los cronistas -Francisco Vásquez, Francisco Ximénez, Antonio de Fuentes y Guzmán- relatan absolutamente nada semejante a lo dicho por Tomás Gage. Andueza, por el contrario, confirma que Gage era religioso dominico que abandonó la orden y se hizo protestante.

María de la Concepción Andueza critica a Gage, por emitir opiniones sin la mesura 
propia de su carácter sacerdotal. Agrega también el dato de que las celdas de las monjas, en aquella época, eran de carácter individual, según la dote que presentaban. Andueza pudo comprobar que Sor Juana de Maldonado vivió en la pobreza, como lo confirma un documento publicado por el profesor J. Joaquín Pardo, hasta el extremo de que la monja solicitó una prensión concedida por el Rey "en consideración de los servicios de su padre y su necesidad". En este fragmento el soberano apunta "que respecto de que por la pobreza en que se hallaba, no había podido pagar la dote de la dicha de su hija, ni los réditos que debía de ella, desde el día de su profesión, ni la cera, ni la sacristía..."

La citada estudiosa confirma la opinión de David Vela en cuanto a que "Tomás Gage tenía una fantasía tan exuberante como poco digna de crédito..."

Por otra parte, en el trabajo de investigación Temas y motivos en la poesía colonial manuscrita de Guatemala, Luz Méndez de la Vega se muestra de acuerdo en que los datos aportados por los estudiosos ya dichos son prueba irrefutable de la existencia de Sor Juana de Maldonado y Paz; Mariano López Mayorical, dice nuestra colega, encontró el primer poema identificado con el nombre de Sor Juana, en la Historia de Carlos V., libro que perteneció a la biblioteca del convento de la Concepción.

Luz Méndez de la Vega añade que en uno de los cuadernillos pertenecientes al $\mathrm{Mu}$ seo del Libro Antiguo de Antigua Guatemala, identificaron el título del primer poema tribuido a Sor Juana: "Décimas a la maternidad de nuestra señora", donde ella creyó ver identidad con las ilustraciones de la obra de López Mayorical; semejanza en rasgos de escritura, en la forma gráfica de colocar las estrofas y el estribillo, así como subrayados y divisiones. Comprobó que era el mismo papel señalado por López Mayorical, así como otros detalles valiosos. Al cotejar una de las páginas de dicho cuadernillo con la página de Mayorical, resultó que sus bordes encajaron con exactitud y se completaron los rasgos de los dos textos. El cuadernillo de Antigua, a que se refiere, tiene varias hojas cortadas, pues en la costura quedaron tirillas cosidas como prueba de las mutilaciones. De aquí la conclusión de que la hoja de Mayorical pudo haber sido cortada del cuadernillo desde hace muchos años, por la diferencia de intensidad de la tinta.

Catalina Barrios y Barrios ha hecho la reconstrucción crítica de la única obra en verso que ha llegado hasta nosotros de Sor Juana y la ha canalizado con mucha fineza, y ha llegado por otro lado a la conclusión de que "haría falta contar con mayor número de textos para llegar a definir las características de la obra poética de Sor Juana. Por ahora baste consignar la existencia de una monja - poeta, cuya obra conocida aparece ingenua y modesta-. Se trata, en todo caso, de un hecho aislado, que no se inscribe en un proceso de desarrollo de la lírica colonial."

Se trata, de todos modos, de una poesía eminentemente religiosa, llena de alegría, bondad y optimismo. El amor que "embriaga" a Sor Juana es un amor profundamente místico, profundo y total, para Jesús a quien llama su Señor. 
Estudiar la poesía de Sor Juana en su totalidad resulta imposible, pues solamente nos llegaron fragmentos y aun ellos son muy pocos para emitir juicios definitivos. Sin embargo, a través de las pocas muestras que nos deja Mariano López Mayorical, se advierte ese amor de proporciones inmensas, místico, que genera felicidad, alegría, paz espiritual, bondad, primor, dulzura, belleza y optimismo.

\section{María Josefa García Granados}

Hay que dejar pasar dos siglos para volver a encontrarse con otra poetisa digna de llamar nuestra atención, y se trata de una profunda y completamente distinta desde todo punto de vista: María Josefa García Granados.

Nació en España, por más señas en el Puerto de Santa María, provincia de Cádiz en Andalucía, pero niña aún, llegó, en 1810 , a Guatemala que fue su patria adoptiva hasta su muerte, acontecida el 29 de julio de 1848 .

Familiares y amigos cariñosamente llamaron Pepita a María Josefa, que contrajo matrimonio con Ramón Saborío, de la Villa de Nicaragua. Manuel Valladares cuenta que después de cinco lustros de vivir en matrimonio, Pepita había dado a su esposo una media docena de niños.

Quizá debido a su carácter fuerte, María Josefa participó en los asuntos políticos de Guatemala, tendencia por la cual pudo fomentar su amistad con todos los hombres relevantes del momento. Desde antes de 1821 ya concurría a las famosas tertulias efectuadas en casa de canónigo José María Castilla, originario de Madrid, España.
María Josefa fue testigo presencial de todos los acontecimientos de la independencia nacional.

César Brañas veía en Pepita a la George Sand de Guatemala, testigo de la vida política guatemalteca provinciana, vida llena de errores, de hombres glorificados sin razón, de una Guatemala atropellada, en que también se sufrió la expatriación y los despojos. Época en que estuvo gobernada por: Morazán, Gálvez y Carrera.

Brañas se duele de que Pepita viviera en un pueblo sumido en la ruina y la miseria, herido siempre, lleno de persecución, y la admira, pues se puso frente a las figuras de la época, las trató con burla, las criticó acremente y a muchas las dejó en ridículo.

En verdad, María Josefa fue amiga personal de Pedro Molina, Barrundia, Diéguez, Valle, Gálvez, Córdova, Aycinena, Milla y del propio Carrera. Pero la más valiosa de sus amistades fue la de José Batres Montúfar, verdadero hermano espiritual de la célebre poetisa que, incluso, participó en las intrigas del gobierno de Mariano Gálvez.

Una especial relevancia merece la relación entre María Josefa García Granados y José Bastres Montúfar. Se dice que fue ella quien enseñó al poeta a cantar y a tocar guitarra.

"En la sala de la casa de la familia García Granados se acostumbraba llevar a cabo íntimas veladas; era aquí en donde ambos conversaban detenidamente. Aquí se hicieron la promesa de contarse después de morir, si existía o no el infierno." 
Según comenta Ramón A. Salazar, José Batres Montúfar vivía, generalmente encerrado y solo Pepita fue su amiga y algunos dicen que fue su "musa gris". Pepita era trece años mayor que Pepe Batres, se quisieron como hermanos y se comprendieron mucho.

Miguel García Granados, en sus Memorias, dice de su hermana mayor:

Mujer de genio independiente, despreocupada, de mucho ingenio y travesura; gran facilidad para versificar, y mucho chiste en sus sátiras; era lo que puede llamarse un ente original y de trato peligroso. ¡Pobre de aquel a quien le ponía la puntería!

Pepita García Granados censuraba acremente. Sus sátiras, manuscritas, en verso y prosa, pasaban de mano en mano y eran recibidas por sus lectores con avidez, quizá porque era la única forma de reírse en aquellos momentos de luchas intestinas y de calamidades colectivas como fue la del "cólera morbus".

Para mantener al pueblo enterado de los últimos acontecimientos, Sanidad publicaba su Boletín del cólera. En contestación, Pepita escribía, su Boletín satírico, del cual tuvo conocimiento José Martí, muchos años después.

El Boletín de Pepita se desarrolló a través de un diálogo entre los médicos miembros de la Junta Directiva, cuyo presidente era Molina. Los otros médicos llevaron los nombres de Bartolo, Juanito, Agapito, Floripundio, Eugenio y Ersilla.

En sus Memorias, Miguel García Granados cuenta que Pepita escribió unos retratos satíricos, dedicados a muchos funcionarios, entre ellos a Morazán; estos manuscritos corrían entre las manos de los habitantes del lugar y como es natural adquirieron popularidad, al punto de que muchas personas los aprendían de memoria. Se dice que en determinado momento fue necesario recurrir a las autoridades para poner fin a tales burlas. Uno de los retratos, por ejemplo, es el dedicado al Dr. Pedro Molina:

¿Veis ese rostro amarillo con esos ojos hundidos,

la boca de sepultura con cuatro dientes podridos?

¡Veis su cuerpo que parece momia, esqueleto o espina...?

¡Esa es la Arpía Molina!

Entre Pepita y Gálvez creció mucho odio y se cuenta, como una paradoja, que, al morir, ambos fueron enterrados en tumbas vecinas y cuando sucedió el terremoto del año 1917 se confundieron las cenizas a los dos.

Además que, de lo anterior, María Josefa García Granados fue autora de varias composiciones poéticas de carácter erótico y hasta, puede decirse, pornográfico por la libertad del lenguaje empleado. Al "Sermón" (que es la más conocida de estas composiciones) hay que añadir el "Himno a la luna" y "A la esperanza"; "A la ceiba de Resolución" ; "A una hermosa joven desgraciadamente enlazada con un achacoso viejo-"“; "A una abeja"; "Plegaria"; "Despedida". También, tradujo algunos versos de Byron. Trabajó la oda heroica y ella misma redactó, en verso, una definición del "pie quebrado".

Se cuenta que en aquellos años, Pepita en compañía de su familia y de amigos 
entre quienes se veía al poeta Pepe Batres Montúfar, se trasladaban a Amatitlán para descansar. Entonces fue cuando la madre de María Josefa, doña María Gertrudis Zavala de García Granados plantó, en la plaza de Amatitlán, dos vástagos de ceiba, los cuales todavía tuvo el gusto de ver crecidos. Luego, Pepita admiró aquellos árboles y así nació su poema "A la ceiba de Amatitlán”. Tanto le agradaba la sombra de la ceiba que le disgustaba pensar verla alguna vez destrozada:

¡Nunca mis tristes

ojos contemplen tu exterminio!

"La Resolución" es uno de los poemas en los que la autora deja señales de desengaño amoroso.

Cuando el 20 de enero de 1835 Guatemala se llenó de cenizas debido a la erupción del Volcán de Cosigüina, de Nicaragua, María Josefa escribió su poema "Descripción de la erupción del Consigüina" como una epístola. Le parece, a Pepita, grandioso el espectáculo por sublime y a la vez pavoroso. Tan tremendo es el impacto de tal erupción para la poetisa, que en una de sus estrofas dice:

La tierra convulsiva se estremece imitando del mar el movimiento; mil columnas al viento eleva la ceniza; y ya parece que el Universo de existir cansado, quiere volver al primitivo estado.

La poetisa describe el horror producido por la erupción del volcán, pero a la vez se advierte en ella un pensamiento lleno de optimismo; decidida a levantarse después de la tragedia:
¡Ah, no más, basta ya: tantos horrores

llenan mi corazón de angustia y duelo:

cubra un funesto velo

este espantoso cuadro de dolores

y en homenaje puro, eterno llanto

derramaré mezclado con mi canto"

Pero, además que poetisa, fue María Josefa García Granados de las primeras periodistas de su país. Según noticias de Agustín Mencos Franco fundó dos periódicos, ambos de contenido político y uno de los dos con carácter también literario.

Debido a las circunstancias, Pepita publicaba con el seudónimo "Juan de las Viñas", para no identificar su calidad de mujer. Ramón Uriarte lo menciona en su Galería Poética y Mencos Franco dice: "La señora, junto con el mismo Pepe Batres, fundaron otro periódico titulado "La Aurora", si mal no recuerdo".

María Josefa García Granados, como lo hace observar Catalina Barrios y Barrios, fue periodista, satírica, romántica. Su interés no quedó fuera de lo erótico. Sus burlas ingeniosas no pudieron despojarse de una buena dosis de amargura. Algunas de sus composiciones perdieron actualidad pues no tuvieron la plena consistencia de la obra acabada. Otros textos dedicados a personalidades de la política, de la medicina, del periodismo, se salvaron porque fueron colaboraciones para medios de comunicación escritos.

"Ahora, al filo de la historia, Pepita se convierte en mujer de leyenda, tal de increíble su actitud dentro de una sociedad en la que aparecía extraordinariamente incomprendida. Ella rompió lazos. Avanzó en campos prohibidos para la mujer. Su lucha fue 
continua, impuso su criterio e hizo valer derechos propios del sexo femenino.

En suma, que es nuestra poetisa una de las personalidades más sobresalientes en la historia de Guatemala. Escandalizó a sus contemporáneos con el estilo desenvuelto de sus textos y con el tratamiento desenfadado de temas eróticos. Su producción aparece recopilada en el libro de Jorge Luis Villacorta, María Josefa García Granados, publicado en 1971.

\section{María Josefa Córdova y Aragón}

María Josefa Córdova y Aragón nació el 29 de noviembre de 1888 en Escuintla, hija de Ignacio Córdova y Benemérita Goyena, hija a su vez del célebre fabulista Rafael García Goyena.

María Josefa contrajo matrimonio con el licenciado Francisco Aragón en 1863, quien fue magistrado de la Corte Suprema de Justicia.

Algunos de sus poemas aparecen en la Galería Poética Centroamericana del escritor Ramón Uriarte. Los poemas son: “A una azucena" y "Contestación a una amiga", de marcado tinte romántico.

No se conoce la fecha de su fallecimiento.

\section{María Cruz}

Cuando ya se había realizado la revolución de 1871 en Guatemala, por lo tanto, dentro de un clima liberal, nace María Cruz el 12 de mayo de 1876 . Hija del poeta Fernando Cruz y María Arroyo de Cruz; vive la amargura de la temprana orfandad materna, junto con sus hermanos Fernando, Matilde y José.

Fernando Cruz se traslada con María a Europa; viven especialmente en París. María viaja por diferentes países: Francia, Italiana, Alemania, Noruega, Dinamarca, los Países Bajos e India. Fija su residencia en París y allá se cultiva. Estudia francés, inglés, alemán, italiano, recibe educación hogareña española-guatemalteca y su preparación escolar se desarrolla en un ambiente francés de finales del siglo XIX.

Cultiva una buena amistad con Domingo Estrada, que también reside en París, amigo que despierta en ella inquietudes poéticas. Estrada influye sobre la personalidad de María, sus gustos literarios y hasta en su estilo. Se suponía un escondido idilio entre ellos. La poetisa principia a escribir poesía, traducción y crónica. No solamente se dedica al cultivo de las bellas letras, María Cruz también pinta y estudia música: piano, arpa, mandolina y guitarra.

"María regresa a Guatemala. La publicación La Locomotora la saluda el 10 de febrero de 1907. Su estancia en su patria es breve, unos meses nada más. En estas fechas ya su obra poética se conocía en nuestros círculos literarios, había cultivado amistad con algunos intelectuales guatemaltecos y extranjeros como eran: Ramón A. Salazar, Agustín Mencos Franco, Antonio Batres Jáuregui, Máximo Soto Hall, Rafael Valle, José Joaquín Palma, Froilán Turcios, Ramón Rosa, Jorge Aguirre y María Herrán.

La poetisa regresa a París, ya sin su padre. Viaja hacia la India en contra de la 
voluntad de quienes la estimaban. En la India fue miembro dentro de la Sociedad Teosófica de Madame Blavatsky. Asiste a conferencias de Madrás, Bombay, Calculta, Brenarés y Sarmath. Estas conferencias se realizan en diferentes idiomas, incluso en bengalí.

Desde la India escribe a sus amigas residentes en París, cartas que más tarde recopilan ellas como homenaje póstumo, con un prólogo bajo las siglas de M. de H. (María Rodezno de Herrán), poetisa centroamericana. A través de estas cartas sabemos que María evoca a su tierra Guatemala:

Qué de cosas deseo hacer a mi regreso en Guatemala hacia la cual siento ahora mis deberes...

María Cruz vuelve a París, después de haber efectuado una magnífica labor benéfica entre los desheredados de la India. Se supone que es allá en donde adquiere una grave enfermedad que la llevó a la tumba. Muere el 22 (o 23) de diciembre de 1915. En estos momentos la acompaña su dama de compañía Mademoiselle Marie Constant. María Cruz fallece precisamente cuando se dedica a prestar sus servicios a los soldados que luchan en las batallas de la primera guerra mundial ya desencadenada. La muerte la sorprende en el momento en que prepara la festividad de la Nochebuena para sus protegidos: mujeres sin trabajo y soldados inválidos."

En la hora de su muerte, María es sepultada en el mismo cementerio parisiense donde reposaban su padre y Domingo Estrada. Curiosamente estos tres literatos guatemaltecos vivieron juntos en Europa, murieron allá, quedaron enterrados muy cerca unos de otros y luego, también juntos, fueron trasladados a Guatemala, por gestiones de la Universidad de San Carlos, por medio de su Rector de turno, Dr. Carlos Martínez Durán.

Buena parte de la labor literaria de María Cruz se encuentra dispersa en periódicos y revistas de la época. La revista La Quince$n a$, dirigida por Ramón Mayorga Rivas de El Salvador, publicó algunas de sus composiciones en los primeros años del siglo. Lástima, dice Máximo Soto Hall, que el nombre de María no se diera a conocer por primera vez en Guatemala sino en El Salvador. La publicación La Locomotora dirigida por Joaquín Méndez y el Diario de Centro América, órganos guatemaltecos de divulgación, recogen algunas de las composiciones de María Cruz.

En todas sus composiciones se dejan ver hondas raíces románticas, aunque no está ausente en ella el conocimiento de lo clásico. Incansable lectora, tuvo en sus manos obras de Baudelaire, Mallarmé, Verlaine y Musset, de cuyos escritos se siente admiradora.

Sus traducciones son: "La Nuit d'Octobre" de Musset y probablemente algunas de Verlaine. A ellas solamente se alude en el Diario de Centro América, el 16 de mayo de 1905. Otros de sus trabajos están dedicados a Baudelaire en: Les Fleurs du Mal, "L'Alabatros" y "La danza macabra", pareada con la traducción efectuada anteriormente por Eduardo Marquina. "Ulaluma", de Poe, es otro de sus traslados a nuestro idioma.

"La labor poética de María Cruz principia a partir de 1900. Muchas de sus poesías se 
publicaron entre 1904-1905, como "Cenizas de Italia”, fechada en Pompeya, el miércoles 10 de febrero de 1902 y reimpresa en Tipografía La Unión, en Guatemala, 1905, con apuntes a modo de diario y sus impresiones por Verona, Venecia, Florencia, Roma, Nápoles, Capri, etc. Más tarde, en 1913, publica Hojas de Loto y Cachemira (versión libre y selección original). Y como muestra de crónicas de viaje puede tomarse la recopilación de sus cartas Lettres de L'Inde, cuya impresión se efectuó en París en 1916. La obra de María fue realizada, tanto en verso como en prosa".

Uno de los estudios más valiosos de la obra de nuestra poetisa lo efectuó César Brañas, por el año 1945, bajo el título de "María Cruz viaja por la India". Brañas se interna por el libro Cartas de Italia y reproduce partes importantes del prólogo firmado por las iniciales M. H. (María Herrán). Este prólogo deja detalles de la personalidad de María Cruz y aplaude el perfecto francés de la poetisa guatemalteca: "María tenía una manera picante y original de expresarse y el don de aprehender al vuelo el lado jocoso de las cosas y los seres. Durante su primera juventud, cedía espontáneamente, en sus charlas y en sus versos, a su disposición satírica. Pero, después con el tiempo, se dedicó a reaccionar contra esa inclinación y, sin que se le escapara nada de los ridículos y las faltas de los otros, se apresuraba a declararlos insignificantes y a las excusas. Ella decía: "Es una verdadera desgracia tener el espíritu dispuesto de tal modo que perciba de inmediato el costado cómico y criticable de todo". César Brañas, por lo de la sátira, califica a María Cruz como la sucesora de Pepita García Granados.
"María Cruz era burlesca, pero también equilibraba sus juicios con una comprensión alta. Sabía reconocer lo bueno oculto en las personas, lo verdaderamente oculto que, según la prologuista, solamente los ojos de María podían descubrir. Toda esa manera suya de ser comprensiva le conquistaba sinceros afectos, de tal modo confidente de los secretos y las penas de los demás, por ello dueña de simpatías. Indulgente, supo hacer mucho bien a la humanidad.

A pesar de su gran comprensión y su don especial para conquistar amistades, María fue tímida. Dice la prologuista de Lettres de L'Inde, "nadie ha atravesado la vida con aire más discreto ni con paso tan silencioso". Logró, sin embargo, en los últimos años, vencer su timidez, aunque poco; siempre continuó modesta. No la envaneció su constante contacto con el mundo diplomático al que la condujo su padre Fernando Cruz. La sola idea de hablar en público la hacía temblar; se consolaba con la idea de que no todos los seres humanos nacen para oradores.

Es a través de las Cartas de la India, en donde el investigador encuentra la presencia de Guatemala en el recuerdo de la poetisa".

Sintetizando, podemos decir de ella que, mujer de fina sensibilidad y variada cultura, dejó escrito y publicado un libro, en francés: Lettres de l'inde (1916), en donde queda testimonio de la huella modernista en estilo y temas. Sus poemas muestran también la simpatía de la autora por el modernismo. Falleció en París en 1915. En 1960 sus restos, juntamente con los de su padre y el poeta Domingo Estrada, fueron 
repatriados por iniciativa de la Universidad de San Carlos de Guatemala. Obra poética: Cenizas de Italia (1905). Una edición selecta de sus poemas fue publicada por la Universidad de San Carlos de Guatemala, en 1961, en edición preparada por María Albertina Gálvez.

\section{Vicenta Rosal}

Nació en Quezaltenango el 27 de octubre de 1815, hija de Encarnación Rosal y de Leocadia Benítez de Rosal.

Desde su infancia demostró inclinaciones religiosas. A la edad de quince años ingresó al convento de Betlemitas, entró al noviciado y en ese momento cambió el nombre de Vicenta Rosal por María Encarnación. Su consagración se efectuó el 20 de enero de 1832.

En el año 1879 sufrió el exilio cuando Justo Rufino Barrios desterró a todas las religiosas. Con este motivo se trasladó a Costa Rica, Colombia y Ecuador en donde murió el 24 de agosto de 1885. Sus restos se conservan en Colombia, en Pasto, Estado de Nariño.

El segundo volumen de Poesía femenina guatemalense rescató a una "Letrilla" de Vicenta Rosal de tema religioso y dedicada a Jesucristo.

\section{Jesús Laparra}

Nació en la ciudad de Quezaltenango el 14 de octubre de 1820, hija de Nicolás Laparra y Desideria Reyes de Laparra.

Ella, como otras mujeres artistas del siglo decinueve, se lamentaba de no haber podido cultivarse para el mejor desarrollo de su talento literario.

Debido a los acontecimientos de 1840 en que Rafael Carrera invadió tierras de Quezaltenango - entonces Estado de los Altos-, Jesús Laparra tuvo necesidad de trasladarse a Comitán, Chiapas, en donde vivió por un tiempo en compañía de su hermana Vicenta Laparra, también poetisa.

Jesús Laparra fundó en Comitán una escuela de oficios domésticos para niñas. En 1854 regresó a Quezaltenango. Ya residente en esta ciudad colaboró con periódicos y revistas de la época, especialmente con el periódico El Ideal.

Su obra literaria quedó publicada en las obras siguientes: Ensayos poéticos poemario (1854), Decenario del Niño Jesús, temas religiosos (1880), Ensueños de la mente, poemario (1884).

En el mismo Decenario del Niño Jesús, agrega un poema: "La huída a Egipto". Algunos de esos poemas los reproducen Poesía femenina guatemalense y La Antología de poetas guatemaltecos. Toda esta poesía se caracteriza por su temática religiosa.

Jesús Laparra murió en la ciudad capital de Guatemala, el día 16 de enero de 1887.

\section{J. Adelaida Chévez}

Nació en la ciudad de Antigua en 1846 y falleció en la ciudad de Guatemala en 1921. Perteneció al Ateneo metropolitano. Fundó con Vicenta y Jesús Laparra, Isabel M. de Castellanos y Carmen P. Silva, el semanario El Ideal. Colaboraron con ellas 
las poetisas: Elisa Monge y Sara María García Salas de Moreno.

Este semanario, El Ideal, merece especial atención por haber sido fundado solamente por mujeres y porque su lema era defender los intereses femeninos. Se luchaba aquí por la igualdad de derechos, podría considerársele como precursora de los derechos de la mujer o la liberación femenina, según opinión de Angelina Acuña y Horacio Figueroa Marroquín.

La vida del semanario El Ideal fue muy corta -cuatro meses-. El primer número salió el 10 de diciembre de 1887 y el último el 28 de abril de 1888.

La única obra de J. Adelaida Chévez (Adelaida Chévez o Adela Chévez) que quedó impresa fue un compendio de economía doméstica. Sus poemas, en cambio, no fueron editados. Se conocen a partir de la Poesía femenina los poemas "Flores y lágrimas" -1881- dedicado a su padre ya fallecido y "¡Su hogar!” dedicado a sus amigos poetas Carmen y Felipe Silva, con fecha 1887.

En la poesía de Adelaida Chévez no se pierde, en fin, la tendencia romántica de la poesía femenina.

\section{Dolores Montenegro}

En la ciudad de Guatemala nació el 8 de noviembre de 1857 Claudia de los Dolores Montenegro, más tarde de Méndez, también conocida como Lola Montenegro; fue hermana de Dominga, Vicente y Miguel.

Dolores Montenegro viajó por varios países: Estados Unidos, Europa, India y Jerusalén.
Su labor literaria fue fecunda y renombrada, como no lo fue la de las poetisas de su tiempo. Colaboró con periódicos y revistas. Especialmente ha de nombrarse su colaboración en El Ideal, órgano publicitario femenino redactado por Carmen P. de Silva, Jesús Laparra y Vicenta Laparra, así como Adelaida Chévez.

Publicó un libro de poemas con el título Flores y Espinas -1887- Se sabe que este poemario llevaba un prólogo de Manuel Coronado Matus, padre del nicaragüense José Coronel Urtecho y que de esta obra de Dolores Montenegro, Enrique Gómez Carrillo dijo: "Casi todas sus composiciones son transparentes como la porcelana japonesa".

Entre 1894 y 1895, publicó su segundo poemario, Versos, prologado por Rafael Spínola. Tanto esta obra como Flores y Espinas se extraviaron; no es posible, por lo tanto, hacer un juicio crítico de ellas. Solamente se conserva la Antología de Lola Montenegro, editada por Rigoberto Bran Azmitia.

Según datos biográficos, la vida misma de Dolores Montenegro fue propicia para que se expresara con tanta amargura, hasta el punto de ser llamada "La poetisa del dolor".

Angelina Acuña y Horacio Figueroa Marroquín, en la Poesía femenina guatemalense, nos trasladan el párrafo siguiente:

En amores fue una gran desdichada: su primer novio resultó ser hermano de su padre, lo que supieron antes de casarse; el segundo la quiso matar por celos suicidándose él después; se casó con el español José R. Torres, quien estando en Sololá como administrador de rentas, fue muerto por un rayo. Contrajo después segundas nupcias con el literato 
salvadoreño Joaquín Méndez, que fue ministro plenipotenciario de Guatemala en Washington. Ambos tuvieron dos hijos: Joaquín, muerto prematuramente, y luz.

De Dolores Montenegro, Otto Oliviera en su obra La literatura en publicaciones periódicas de Guatemala, opina que "fue una escritora más bien espontánea, con defectos por su falta de educación literaria, pero no por ello deja de ser sincera y apasionada". Hasta el punto, Olivera ve en ella el ardor de la pasión que la coloca "entre las precursoras de las grandes poetisas del amor conocidas en el siglo veinte: Gabriela Mistral, Delmira Agustini, Juana de Ibarbouru y Alfonsina Storni”.

Aun cuando el amor es un tema fecundo en la poesía de Lola Montenegro, otros temas como el dolor, la amistad y cierta devoción familiar la constituyen. Esta poetisa refleja, pues, intensidad en sus penas, quejas atormentadas por sus desengaños y desilusiones, pasiones avasalladoras. La muerte de su hermana Dominga provocó a Dolores un grito desgarrador de soledad. A estas amarguras agreguemos el dolor producido por el fusilamiento de su hermano en 1889.

Parece como si Dolores se refugiara en la religión. Sus poemas toman un sabor bíblico. La libertad es otro motivo de su canto. Le interesa la unión centroamericana y así rinde culto a Justo Rufino Barrios, su contemporáneo.

Dolores Montenegro murió a la edad de 76 años -1933-, en la capital de Guatemala.

\section{Isabel M. de Castellanos}

De esta poetisa solamente se conoce el poema "En la corona fúnebre del literato don José Milla", con fecha 1885 . Este poema es una exaltación del novelista guatemalteco:

Al ramo más difícil de la literatura tú fuiste quien al campo primero la lanzó de cuadros de costumbres hiciste la pintura que hallando irregulares tu juicio criticó.

Más adelante muestra cómo Milla fue lector cotizado en el siglo diecinueve:

Por eso tu recuerdo grabado en mi memoria tendré mientras que viva y aliente el corazón recuerdo que hace la honra de nuestra patria historia, que inspira simpatía, profunda admiración.

No se conoce, de Isabel M. de Castellanos, ninguna otra fecha ni dato biográfico, mucho menos su labor literaria completa.

\section{Pilar Larrave de Castellanos}

Finalmente encontramos en la Poesía femenina guatemalense, el poema dedicado a "Santo Tomás Chichicastenango", el 15 de septiembre de 1894, firmado por esta poetisa de quien no se conoce ningún otro dato biográfico ni tampoco algo más de su obra literaria.

En este poema dedicado a Chichicastenango, Pilar describe el paisaje y termina con los versos:

...Ah! Cuánto me recuerdas de dramas olvidados, soberbia, aunque silvestre, feliz Santo Tomás! ¡Tus arcos y tus flechas, tus nombres espantados, la sangre a borbotones y el odio siempre audaz!

En resumen, si queremos decirlo con Catalina Barrios Barrios, la poesía guatemalteca 
del siglo diecinueve todavía no ha sido localizada en su totalidad. Bástenos saber que todas las composiciones han quedado dispersas en periódicos y revistas. Por lo tanto, una de las conclusiones más valederas posiblemente esté en que la mujer ha colaborado desde hace más de un siglo con la prensa del país y que ha resultado, incluso, fundadora de sus propios órganos publicitarios, algunos, como El Ideal, precursores de la liberación femenina que, en los últimos decenios del siglo veinte, alcanza vuelos insospechados.

\section{Vicenta La Parra de la Cerda}

Vicenta La Parra de la Cerda nació en Quetzaltenango, Guatemala, el 5 de abril de 1831, hija de Nicolás La Parra y de Desideria Reyes, ambos de modesta condición social y escasos recursos económicos. Huérfana de madre a los cuatro años -según otros biógrafos a los seis- fue criada prácticamente por su hermana la poetisa Jesús (1820-1887), por la que sintió siempre mucho apego. Tenía Vicenta nueve años cuanto la familia La Parra se trasladó a Comitán de las Flores, en México, donde residió unos diez años, tras los cuales regresó a Guatemala. Animada desde su primera infancia por una genérica vocación artística, la futura escritora estudió música y canto, participando en los numerosos conciertos que don Juan Matheu organizaba en beneficio del futuro Teatro Cabrera (más tarde Teatro Colón) entonces en vías de construcción. En 1853 se casó con don César de la Cerda, descendiente de una noble familia española, pero a los pocos años tuvo que volver a abandonar Guatemala, siguiendo a su marido, seriamente comprometido en conspiraciones e intrigas políticas. Los años de exilio van de 1858 a 1864 y la pareja se establece primero en El Salvador, después en Costa Rica y nuevamente en El Salvador.

Tanto en Santa Ana de El Salvador, como en San José de Costa Rica, Vicenta La Parra de la Cerda dirigió centros escolares femeninos y durante el período costarricense perdió a dos hijos, Ángela y Ceyetano. Tras regresar una vez más a su patria en 1864, sufrió en 1866, como consecuencia de un nuevo embarazo, una parálisis que la tuvo inmovilizada en la cama durante años (de ahí la denominación de "poetisa cautiva") hasta que una feliz intervención del doctor Miguel Valladres, eminente clínico que acababa de regresar de Europa, mejoró sensiblemente sus condiciones. Los largos años de inmovilidad forzosa no doblegaron el temple de la escritora que, por el contrario, se dedicó con más ahínco a su actividad literaria publicando versos -más tarde recopilados en volúmenes- y las que podemos definir como las primeras obras de teatro de la Guatemala moderna.

Tras tantas desgracias y amarguras que sin duda marcaron su carácter y contribuyeron a determinar su pesimista visión de la vida, toda ella impregnada de añoranzas, tristezas y desesperaciones, llegaron finalmente el éxito de público y los reconocimientos oficiales, como una pensión vitalicia que le fue concedida en julio de 1886 como consecuencia del clamoroso triunfo de su drama El ángel caído y, ocho años más tarde la concesión por parte del entonces Presidente de la República, general Reyna Barrios, de los derechos de autor de la totalidad de su producción dramática. 
Además de ser autora de poesías, dramas y novelas -en realidad ni buenas ni malasVicenta La Parra se dedicó activamente al periodismo, fundando primeramente junto con su hermana Jesús, el más antiguo hebdomadario femenino guatemalteco, $\mathrm{La} \mathrm{Voz}$ de la Mujer, entrando a formar parte sucesivamente, en 1887, con Lola Montenegro de Méndez, Carmen P. de Silva y Adelaida Chávez de Pineda, de la redacción del periódico literario El Ideal. Miembro honorario de la Asociación de Escritores y Artistas Españoles, de la Asociacion de Escritores y Artistas Guatemaltecos y de análogas corporaciones de El Salvador y de Hondura, tras alcanzar finalmente la notoriedad y ser considerada una especie de institución nacional, doña Vicenta murió en Guatemala el 29 de enero de 1905. Cuarenta años más tarde, en julio 1945, siendo ministro de Educación Nacional el dramaturgo Manuel Galich, le fue dedicada una escuela femenina en la ciudad de Guatemala.

Además de los libros de poesía y las novelas, obras a las cuales ya hemos aludido, doña Vicenta nos ha legado cinco dramas: Tempestades del alma, La virtud a prueba, El ángel caído, Los lazos del crimen e Hija maldita. Fueron obras representadas numerosas veces en su patria, obras a las cuales sonrió un indiscutible éxito de público y de crítica; fueron éxitos que contribuyeron, en vida de la autora a hacer de ella una de las figuras más representativas de la literatura de su tiempo. En realidad, al releer esos dramas hoy (no cabe decir al asistir a su representación, ya que ninguna compañía tendría, suponemos, el valor de reponerlos, a menos que se tratara de un festival retrospectivo o de espectáculos de carácter didáctico), releyendo esos dramas hoy, decíamos, cuesta entender las razones de tanto éxito y de tan viva popularidad. Si bien es cierto que las fechas entre las cuales se cumple la trayectoria vital de doña Vicenta corresponden, grosso modo, al florecimiento de un gusto literario de exasperado romanticismo naturalista y de folletín, también es cierto que la autora de Hija maldita tiene tal tendencia a exagerar que resulta inadecuada toda justificación que pudiera alegarse a cuenta de situaciones culturales, evoluciones sociales, chovinismos nacionalistas o cosas por el estilo.

La atmósfera, los ideales, el clima, el ambiente -este último- con las inetivables adaptaciones a la específica situación de Guatemala, la forma de sentir y de pensar común del teatro de La Parra son, con poquísimas variantes, los de la dumasiana Dama de las Camelias. Los títulos de sus dramas bastan por sí solos para sugerirnos el clima en el que se desarrollan: personalidades exasperadas, situaciones desorbitadas, lances repentinos, felices desenlaces tras aventuras increíbles, patrones fácilmente intuibles desde un principio, contraposiciones obligadas y descontadas de caracteres amanerados, carentes de matices, todos de una pieza, lucha sin cuartel entre el bien y el mal, denuncia de prejuicios sociales y de trasnochados convencionalismos, todo esto constituye el bagaje de la escritora, cuyos dramas, bien mirados, poco tienen que perder o ganar comparados con todo un repertorio europeo contemporáneo, desde las obras, por ejemplo de Echegaray a las de Paolo Giacometti, de Felipe Derblay a Los dos sargentos, de La novela de un joven pobre a La muerte civil. 
Los caracteres son exasperados más allá de toda credibilidad, tanto cuando retratan a los malvados, como cuando representan a los buenos. Resultan casi insoportables precisamente por exceso: véanse a Marcos en El ángel caído, Rodrigo en Hija maldita y sobre todo, Carlos en Tempestades del alma. (De paso conviene notar que los tres tipos masculinos constituyen sustancialmente un carácter único y son tres nombres de un mismo personaje). En cuanto a los personajes femeninos, basta con ver a Tula en Hija maldita, dulzona en su bondad hasta el empalago. Suelen ser por lo general figuras muy poco humanas precisamente por improbables, poco auténticas e inverosímiles, que actúan con grandilocuencia, sin perder ocasión para sentenciar o discurrir sobre los casos de la vida en abstracto, casi diríamos olvidados de las enmarañadas situaciones en que los ha colocado la autora, hasta el punto de que encontramos maridos traicionados, padres virtuosos y desesperados, amantes hartos de sus compañeras, divagando de forma didáctico-ilustrativa, no sólo acerca de su situación personal, sino también, y aún más, acerca de cómo anda el mundo. $\mathrm{Y}$ esto, por lo general, en los momentos de mayor intensidad, cuando más rápida y cautivadora debería proceder la acción. La acción -conviene recordarlo en passant- además de estancarse tediosamente, se reduce en ocasiones a mera narración, a prolijos resúmenes de acontecimientos acaecidos con anterioridad o al mismo tiempo que otros y que los distintos personajes, por turno, se encargan de contarle al público, para mejor comprensión de la acción escénica.
Al igual que en el teatro de ascendencia clásica-digamos de Molière o de Goldoni-, donde nunca falta la pareja de fieles y devotos criados que, al subir el talón, le narran al culto y distinguido público las historias de la familia; en el teatro de doña Vicenta siempre hay un par de complacientes secretarios, empleados de confianza, servidores o protegidos que nos ponen periódicamente al corriente de la situación, como Pedro y Rosa en Tempestades del alma o Isabel y Agustín en El ángel caído.

Sería difícil, aun con la mejor voluntad, dar fe de la fértil y arrebatada inventiva de la escritora. Los personajes, como hemos dicho, son siempre los mismos, como salidos de un mismo molde, y por lo que respecta a las situaciones, estas se repiten hasta la saciedad. Puede ocurrir que escenas enteras de un drama hallen su exacta correspondencia en escenas análogas de otras obras, hasta el punto de que bajo este aspecto, su teatro se puede definir como larga serie de variaciones sobre tres o cuatro temas constantemente reiterados: el adulterio, la maldad que insidia la pureza, la pasión por el lujo, el amor puro y generoso que, aun tras el desengaño, "no muere", la desesperación de un anciano padre muerto o anonadado por el dolor ocasionado por el "desliz" de la hija y unas pocas situaciones más. En estos dramas hay siempre un hijo inocente de tres, cuatro o cinco años, por cuyo amor el padre traicionado no se suicida cuando la esposa huye con el amante, o para volver al cual -talvez al cabo de veinte años- la madre, después de alcanzar el último grado de degradación social, afronta riesgos y situaciones fantásticas e incluso se redime, aunque sea in articulo mortis. Y al igual que un hijo 
inocente, siempre hay también un anciano padre, a lo Germont, celoso guardián del honor de su hija, que sermonea y, en cuanto se presenta la ocasión, se bate en un duelo con el yerno ruin y calumniador.

Tampoco faltan personajes que, nada más al conocerse, empujados el uno en brazos del otro por inexplicables simpatías y misteriosas afinidades, deciden autoadoptarse como hermanos, padres o hijos. En cada drama, con regularidad, la protagonista se desmaya mientras se intensifican a su alrededor los "apartes" de conmiseración de los demás y no menos regularmente algunos intérpretes de la historia, convenientemente ocultos tras un cortinaje o una estatua en el jardín, oyen y ven lo que deberán ignorar y que -de ignorarlo de verdad o no llegar a enterarse de forma tan peregrina- pondrían en apuros a la autora para el ulterior desarrollo del rocambolesco enredo. Con este fin, a veces, también acuden en su ayuda cartas y misivas perdidas azarosamente y encontradas en el momento oportuno, o bien regresos casuales, gratuitas entradas en escena y otros recursos semejantes. Huelga decir que los personajes raras veces actúan obedeciendo a una lógica interna y más a menudo entran y salen de escena solo en función del efecto que la autora necesita crear en ese determinado momento.

En las caracterizaciones, como hemos dicho, doña Vicenta recarga las tintas. Sus personajes son siempre del todo buenos o del todo malos, sin medios términos, y se revelan desde la primera frase. En algunas figuras secundarias, poco más que "tipos", asistimos a una ingenua esquematización del "sano sentido común del pueblo" e incluso al modesto intento de introducir una nota cómica en el drama. Conforme al gusto y a la técnica de la época, estos románticos personajes (uno de ellos se define a sí mismo como "alma para amar nacida") usan y abusan abiertamente del monólogo, al igual que ocurre en los libretos del melodrama lírico, cuando la soprano, el tenor o el barítono, solos en la escena, entonan, tras un recitado más o menos largo, su romanza, llena de trinos, gorjeos y virtuosismos canoros. Observamos, ya que hemos sacado a colación la ópera lírica, que el teatro de doña Vicenta posee no pocas características formales y estructurales del melodrama. Algunos "comprimarios" evocan inmediatamente la función de los coros en la ópera; hay ciertos "cuartetos" subdivididos internamente en doble dueto de personajes que se ignoran mutuamente, a la manera, digamos, del célebre cuarteto del Acto IV de Rigoletto; ciertos finales, ciertas entradas, atraen a la memoria las garbosas cabaletas de la ópera italiana ochocentista; véase, por ejemplo, la escena de Hija maldita en la que Jacinta, una modesta Celestina doméstica, convence a la protagonista de tener un encuentro con el galán aborrecido por el padre.

No creemos que se trate de meras coincidencias. En aquellos años, numerosas compañías de ópera se alternaron en los escenarios centroamericanos y la influencia del género no debe ser descuidada.

Cuáles son el estilo y el lenguaje de estos personajes se intuye, suponemos, por lo que hemos venido diciendo hasta ahora. El amor es siempre un incendio, y de tales proporciones "que abrasa el mundo", una auténtica llamarada: 
... esta pasión hoguera

que oculta en mi pecho arde

me arroja en la horrible senda

que recorren los infames.

El seductor es aquel al cual es imposible dejar de amarle, "porque ese hombre me fascina/ me trastorna, me enloquece/ su mirada me enternece/ y me atrae... y me domina". El adulterio "es amor maldito/ que Dios y el mundo reprueban/ amor que a los hombres lleva/ a los antros del delito". La esposa infiel escucha "aterrada" la voz del remordimiento en estos términos:

\author{
¡Adúltera!, dice el viento \\ en su canto melodioso. \\ ¡Adúltera!, dice el ave \\ murmurando en la enramada, \\ y repite el bosque umbroso: \\ ¡Adúltera!, con voz grave. \\ Sufre adúltera que engañas \\ dice la brisa gimiendo. \\ ¡Sufre!, me grita rugiendo \\ el eco de las montañas. \\ Adúltera maldecida \\ me dice en su enojo el cielo \\ jamás enviaré el consuelo \\ al desierto de tu vida.
}

El recuerdo de la esposa infiel constituye para el marido "una llama/ una encendida tea/ que en mi cerebro flamea/ y me abrasa el corazón"; la protagonista "siempre está bebiendo/ el veneno del dolor", ya que no puede olvidar que "el beso de su boca/ va destilando veneno/ y más inmundo que el cieno/ puede manchar lo que toca": la esposa desleal se convierte en "una esposa perjura/ que hundida en el fango inmundo/ va devorando en el mundo/ los desprecios que le dan!" Naturalmente, si no existe adulterio y la mujer es pura, ella posee un tesoro: "el armiño/ de aquella frente más pura/ que las gotas del rocío/ que sorben suave aroma/ de los nardos y el tomillo". Luego las tentaciones de la vida la transforman en una "nave perdida/ que sin rumbo fijo flota/ en un océano de hiel/ desmantelado bajel/ que la tempestad azota".

Es curioso observar que doña Vicenta crea repetidas veces, según hemos destacado, un ejemplar de mujer, típicamente romántico, por otra parte, joven, hermosa, rica, afortunada, que lo tiene todo para ser feliz y que, infaliblemente, tropieza y se autodestruye por su propia debilidad, por su incapacidad para resistir a las tentaciones de un mundo más o menos corrompido y corruptor. Diríamos, incluso, que hay un matiz de complacencia, de sádica complacencia en acompañarla paso a paso, primero en las peligrosas intrigas amorosas, después en la ruina y en la degradación que son su consecuencia. En estas criaturas hermosas, jóvenes y afortunadas, doña Vicenta tiende casi siempre a descubrir el mal, lo moralmente bajo y, por supuesto, a fustigarlo sin piedad. Ya en uno de sus anteriores poemas cantó: "No hay amistades/. Todo es engaño; / en los amores no tengo fe. / Mató esas creencias el desengaño/ sin dejar sombra de lo que fue", y al igual que la Matilde de Hija maldita, en varias ocasiones se ensaña en la sin duda despreciable Jacinta (que por añadidura está muerta). También la poetisa nos revela a veces unas uñas afiladas y escasos sentimientos de caridad cristiana, como cuando habla de dejar la vida: "Pero al dejarla quiero / que se ahogue en llanto la humanidad! / Quiero que sienta lo que yo siento / quiero que llore como lloro yo, / quiero brindarle todo el tormento/ que en copa de oro mí me dió. / Quiero burlarme de sus dolores/ reirme quiero de su aflicción/ 
porque ha tronchado las bellas flores/ que coronaban mi corazón”. ¿Es este un simple pretexto literario, una pose, o es por el contrario el resultado de muchos años de infelicidad y dolor? Los mismos que hicieron brotar el amargo lamento: "Vivir como yo vivo/ sumida en la pobreza/ bajo el terrible azote de la adversidad/ cubierta con las sombras de fúnebre tristeza/ sufriendo los martirios de cruel enfermedad." ¿No habrá sido ese estado de ánimo agrio el que determinó una especie de inconsciente envidia, de inconfesada animosidad frente a esas criaturas afortunadas a las que ella nunca pudo parecerse? No son más que hipótesis psicológicas, pero podrían arrojar algún atisbo de luz sobre la poética de Vicenta La Parra de la Cerda. No hay duda de que varios fragmentos de su obra dramática revelan claramente situaciones autobiográficas y algunas frases demuestran que doña Vicenta se identificaba con los personajes dolientes y desgraciados.

¿Qué es lo que permanece vivo en la obra dramática de esta escritora? Muy poco, si consideramos sus obras sólo desde el punto de vista estético. Ninguna originalidad, ninguna aportación nueva, ninguna creación capaz de desafiar el tiempo y de sobrevivir el gusto de la época (¿no fue Wilde quien dijo que había que tener mucho gusto para sustraerse al gusto de la propia época?...), ningún rescate en el plano documental y una versificación insulsa, vulgar, henchida de lugares comunes, de redundancias y trivialidades. $\mathrm{Si}$ se piensa, por ejemplo, que cuando el público le tributaba ovaciones y los críticos alababan su poesía había aparecido ya en el horizonte de la lírica hispanoamericana la estrella de Rubén Darío, no queda sino llegar a la conclusión de que doña Vicenta no se eleva por encima del plano de la mediocridad má anodina y convencional. Pero toda medalla tiene su reverso y no conviene olvidar que fue precisamente la autora de Hija maldita -si bien junto con otros escritores- la creadora, o la restauradora, si se prefiere, de un género literario nuevo o cuando menos desusado en Guatemala, el teatro, al que indudablemente contribuyó a acercar o volver a aproximar a grandes masas de la población. El teatro en América Central, como se ha dicho en otras ocasiones, no ha sido nunca popular y no ha tenido una vida fácil. Haber contribuido a su difusión, aunque sea en formas rudimentarias e ingenuas, aunque perfectamente acordes con el momento histórico, como lo demuestran su éxito y popularidad, no es mérito que deba menospreciarse. El posterior florecimiento de autores como Ismael Cerna (1856-1901), Manuel Valle (1864-1913), Rafael Valle (1898-1922), Trinidad Coronado (18481917) y otros; el más difuso y generalizado "habitus" teatral de Guatemala "fin de sièle" y del primer ventenio del siglo XX, han podido verificarse, entre otras cosas, gracias a la labor, llamémosla "pionera", de doña Vicenta. Debe reconocérsele, por consiguiente, una notable importancia y una función francamente positiva desde una perspectiva histórica.

\section{Adela Sagastume de Acuña}

Adela Sagastume de Acuña nació en la Hacienda La Esperanza, municipio de San Pedro Pinula, del departamento de Jalapa. Dejó de existir el 22 de abril de 1926. Su producción poética quedó en cuadernos manuscritos, de donde se obtuvieron los 
poemas que forman el volumen Sensitivas, y la influencia de Gustavo Adolfo Bécquer es indiscutible, como lo muestra su poema "A Pinula", dedicado a su hermano Maximiliano, y que se inicia así: "Volverán las auroras nacaradas/ en tu seno su luz a reflejar/ y al albor de sus rayos matutinos/ feliz despertarás..."

\section{Amanda Montenegro y Montenegro}

Sobrina de la poetisa Lola Montenegro, tomó parte activa en la política del país en manifestaciones que provocaron la caída de Manuel Estrada Cabrera. En el periódico La Hora escribió artículos de ataque hacia el gobierno de turno. Además editó los poemarios Hermana Vida y Polvo de estrellas.

\section{Anita Martínez Aguilar (1898)}

Nació en Quezaltenango, publicó sus primeros versos en periódicos escolares del Instituro de Varones de Occidente; luego escribió en el Diario La Tarde de la ciudad capital, periódico dirigido por Ernesto Carrera, y en Fígaro de Managua, Nicaragua. Su poesía se divulgó en la antología Valores de América, Montevideo, Uruguay (1949-50).

\section{Blanca Granados de Rosada (1909)}

Fundó con sus hermanas Jenny y María el quincenal Espigas sueltas, del cual fue directora. Sus versos contienen temas místicos y exaltación a la mujer, especialmente a la madre.

\section{Celinda P. Varmes (1846-1932)}

Nació en Antigua, Guatemala. Los escasos versos de ella que se han podido leer son poco extensos y denotan cuidado en la métrica y la rima; revelan su afición hacia la música, la naturaleza y al amor romántico y sentimental al estilo de la novela $\mathrm{Ma}$ ría de Jorge Isaacs.

\section{Elena Guerra de Sandoval}

Nació en San Pedro Pinula, del departamento de Jalapa. En varios concursos literarios obtuvo premios (por ejemplo, Jalapa, 1927 y Chiquimula, 1938-1947); sus obras son: Voces de América y sus grandes hombres (dramatización), Somos americanos (versos con sentido panamericanista), La última versión de un poeta (Artigas) (drama histórico), Amor salvaje (obra dramática con escenas propias de la Conquista de América), La importancia del saber (comedia infantil), El descubrimiento de América (dramatización), Nociones de Psicología pedagógica (tratado para estudio), La envidiosa (comedia educativa), La ladrona (monólogo) y El triunfo de las mujeres (exaltación femenina). Como se ve, la mayoría de su obra es de tipo didáctico. Sus versos se inclinan hacia lo histórico, la exaltación de la raza indígena y lo amoroso romántico.

\section{Julia Solís Gallardo (1908)}

Nació en Guatemala. Su producción literaria se inició en 1920 y sus publicaciones han quedado en la revista mexicana En guardia, en la revista guatemalteca Trópico y en el diario El Imparcial. Sus versos más conocidos son Elegías para la madre.

\section{Lola Villacorta Vidaurre}

Nació en Cobán. Por su obra pedagógica y literaria mereció la Orden Francisco Marroquín (1967). Escribió algunas obras 
teatrales como: La tinaja maravillosa, Xucarneb, Campánulas azules, 15 de septiembre de 1821, Yerba mora -cuentos regionales-, Breves datos geográficos e históricos de Alta Verapaz. Varios órganos de prensa conservan leyendas que ella recopiló. Como muchas de las escritoras aquí mencionadas, su poesía no escapa de lo circunstancial con base histórica.

\section{Luz Valle}

Nació en la ciudad capital de Guatemala el 19 de octubre de 1896 y falleció el 3 de mayo de 1971. Hija del licenciado Manuel Valle - periodista, escritor y poeta- y doña Amalia Hernández de Valle. Sus hermanos fueron también personas destacadas en la sociedad guatemalteca: doctor Manuel Valle Hernández, miembro de la Cruz Roja; el orador, comediógrafo y escritor laureado licenciado Rafael Valle; el periodista José Valle, cuyo seudónimo fue Pepe Gris, destacado por su gran humorismo, y la declamadora Amalia Valle de Figueroa.

Luz Valle desempeñó varios puestos en el campo docente y artístico del país. Fue directora del programa "La voz del hogar"; fundadora de la Cruz Roja Roja Guatemalteca; directora y fundadora de la revista Nosotras (1933-1943); jefa de redacción de la revista Espiral; colaboradora de la revista Senderos; iniciadora del diario El Imparcial, en donde tuvo a su cargo la "Página del hogar"; autora de obras de teatro, poemas para niños, dramatizaciones, rondas $\mathrm{y}$, además, colaboradora de diarios y revistas, como el Diario de Centro América, Revista de la Cruz Roja, Revista Azul, revista El Niño, Revista de Educación, revista Vida, en donde ha quedado su producción. Catedrática de literatura preceptiva y de teatro. Fundadora del grupo "Gabriela Mistral".

Luz Valle, autora de la generación del 20, no siempre publicó con su nombre, pues en algunos de sus textos se encuentra el seudónimo de Aurora Boreal.

Sus obras son: El milagro de septiembre, puesta en escena en todo el país, La cruz de diamantes, estrenada en el Instituto de Señoritas Belén; Ronda de la sierra, escrita con motivo de la muerte de Gabriela Mistral; En vísperas de la libertad, estrenada en el citado Instituto. Así es mamá, en honor a las madres, estrenada en igual lugar; Cromo de antaño; Estampas de la independencia, teatro de títeres.

Luz Valle ganó el primer premio en los Juegos Flores de Quezaltenango con su obra teatral La Revancha (1919).

De su obra lírica, León Aguilera dice: "ninguna escuela la apresó, ninguna tendencia la sometió a ningún freno". Sin embargo, basta leer unos de sus primeros versos para encontrar marcada tendencia modernista por su gusto hacia la pedrería y por el ritmo en tendencia modernista en que Darío surge como su maestro. Oigámoslo en el poema "Mi regalo de hoy":

Papaíto tuve un sueño
que ahora voy a contar
pues soñé que yo era dueña
de un lindísimo lugar.
Había ríos de leche
para poderse bañar
y montañas de escabeche
y volcanes de caviar.
Un estanque delicioso
cuajado de macarelas,

Papaíto tuve un sueño ontar pues soñé que yo era dueña de un lindísimo lugar. Había ríos de leche para poderse bañar y montañas de escabeche y volcanes de caviar. cuajado de macarelas, 
y un bosque muy primoroso

de guindas y de ciruelas.

Había patos prensados

jamones, ricos pasteles

y dulces tan delicados

que hasta destilaban mieles.

Y en mi sueño yo decía

¿Sería mentira o verdad?

Con qué gusto le daría

esta tierra a mi papá.

Como puede observarse, Luz Valle introdujo en este poema algunas palabras que no solamente resultarían extrañas frente a la poesía romántica, que hasta la fecha se estaba escribiendo, sino acusa una marcada tendencia a la sinestesia; está presente el gusto en la nota diversa de alimentos, la vista en tanto se refiere al paisaje, el color marcado en lo blanco de la leche y otros que matizan en mieles y frutas. Esta es una muestra, sacada de sus publicaciones en $E l$ Imparcial. No se conoce ningún poemario de ella, como no sea algunas de sus piezas líricas que forman parte de antologías.

En la revista Nosotras escribió algunos cuentos cuyo tema es predominantemente religioso, casi siempre dirigidos a la niñez- de momento no es posible dejar sentados otros juicios, toda vez que no se ha divulgado su obra inédita y no ha sido posible revisar la colección completa de tal revista, en cuyas páginas Luz Valle trató de reunir colaboraciones muy valiosas de los más altos representantes de la literatura guatemalteca. Lamentablemente en nuestro medio hay publicaciones que tienden a morir pronto. La revista Nosotras, a pesar de que se inició con mucho empuje y de que se vio estimulada con anuncios de altas instituciones, vivió pocos años. Prueba de la decadencia económica que la hizo morir está en el valor del ejemplar que al principio fue de veinte centavos de quetzal y en los últimos números bajó a diez centavos, mitad del precio inicial.

\section{María Granados}

Su nombre usual es María G. viuda de Grajeda, con sus hermanas Blanca y Jenny publicó el periódico quincenal Espigas sueltas (1929). Colaboradora del periódico El grito del pueblo, cuyo fundador y director fuera su padre. Los libros publicados de su cosecha son: Mujer en soledad (poemario) y Celeste y rosa (poemas infantiles). Sus libros inéditos son: La fugaz primavera (cuentos para adolescentes) y Lámpara solitaria (pensamientos breves). Su poesía conserva un marcado amor a la patria y temática amorosa romántica por su amor a la naturaleza.

\section{María del Pilar}

Nació en Guatemala. Usó el seudónimo literario Flor de Lys, con el cual empezó a colaborar en los periódicos y revistas de la capital y centroamericanos. Fue miembro de varias instituciones culturales. Obtuvo mención honorífica con su cuento "Navidad", en el certamen literario quezalteco de 1928. Sus obras publicadas son: Onix (1919) y Sinfonía de la luz (1942). La publicación de estos libros la hizo acreedora a su diploma en la Feria del libro de la capital mexicana. Su obra inédita: Rondas de luna (poemas infantiles) y Alas (poemas). En sus poemas la soledad es un tema básico.

\section{Roquelita Tobar de Álvarez}

$\mathrm{Su}$ producción ha quedado publicada en Antología de poetas jutiapanecos. En 
Jutiapa publicó varios periódicos escolares y el mensuario cultural Avance.

\section{Rosa Jáurequi Montes (1904-1967)}

De ella se organizó un poemario póstumo bajo el título de Vida en azul (1969). El teatro de la Municipalidad llevó a cabo la representación de su Pastorela.

\section{Consideraciones finales}

Como se puede comprobar por las páginas anteriores son bastantes los nombres de mujeres que han aparecido en la literatura guatemalteca, pero debido a que las condiciones económicas no lo han permitido, los volúmenes divulgados son relativamente pocos, y de aquí la dificultad para que el investigador pueda emitir un juicio definitivo y ecuánime. Como la mayoría ha publicado en periódicos y revistas, se hace necesario un trabajo minucioso y previo de recopilación para que tal obra resulte sustitutiva de las ediciones sin divulgarse. Así, este trabajo se basa, por una parte, en las antologías, que no siempre reúnen lo mejor de la producción ni están actualizadas, y por la otra, en estudios realizados y en la lectura de los volúmenes que ha sido posible encontrar, pues muchos de ellos están agotados o bien no/se encuentran en las bibliotecas públicas o privadas, ni mucho menos en las librerías a las que se ha tenido acceso.

Han sido además de suma utilidad los trabajos citados al principio de esta investigación, de la Licda. Catalina Barrios y Barrios y del Lic. Francisco Albizurez Palma. De sus trabajos hemos sacado gran parte de la información relativa a nuestras biografiadas y así queremos dejarlo aclarado. El análisis, de todos modos, no resulta exhaustivo, pero sí abre brecha para futuros estudios efectuados con mayor detenimiento.

La labor de la mujer en la literatura guatemalteca de los primeros decenios del siglo veinte, según lo apunta un crítico que ha dedicado muchos estudios a la literatura guatemalteca moderna, resulta ser notable en poesía, y no así en la narrativa, pues esta se ha dado con mayor fecundidad más allá de los años treinta y su estudio.

Como ya se ha dicho, recurrimos a los volúmenes antológicos: La poesía femenina guatemalense, por ejemplo, organizada por Angelina Acuña de Castañeda y Horacio Figueroa Marroquín, que contiene datos biográficos y muestras que no son siempre las mejores; se ha incluido en ella la obra de mujeres, aunque hayan escrito muy pocos versos y por lo tanto no se hayan perfilado como escritoras consagradas ni tampoco den la pauta para considerarlas como promisorias. Este libro de Angelina y Figueroa Marroquín se publicó como homenaje a la mujer guatemalense en 1975, Año Internacional de la mujer. Se diría que no se cumplen en él los requisitos más serios que una antología pide, por ejemplo, seleccionar mayor relieve en calidad, sino más bien que se ha hecho con fines de divulgación y estímulo para la mujer que ama la poesía. De la Poesía femenina hemos seleccionado personas que nacieron o se iniciaron como escritoras en los últimos años del siglo diecinueve o los primeros decenios del veinte. 
La Antología de poetas guatemaltecos antiguos y contemporáneos- (1750-1970) en que se incluye la antigua recopilación de Humberto Porta Mencos (1928) y la nueva de Hugo Rolando Corado (1970) y editada en 1972, también ha sido guía útil para nuestros propósitos.

La obra literaria de la mujer guatemalteca en su parte fundamental, como ya dijimos, ha sido poética, de marcada tendencia romántica y más o menos de temática similar: amorosa, religiosa, circunstancial. Lo social es escaso. Una buena parte es didáctica y dramática.

Por de pronto dos conclusiones se pueden sacar de la lectura de la producción literaria de estas poetisas de ayer y son que ni el atrevimiento en materia erótica ni la reivindicación de los "derechos" femeninos son típicos de las generaciones de hoy. Tanto en el primer caso como en el segundo las escritoras del siglo XIX y de las primeras décadas del $\mathrm{XX}$ demostraron ser capaces de luchar, y con tesón, para lograr las conquistas que sus continuadoras, a veces, juzgan monopolio de su época y de su desafiante actitud. 
